\title{
The Shuhi House between Reformist China and Revivalist Tibet
}

\section{Journal Article}

Author(s):

Huber, Franz K.; Weckerle, Caroline S.; Hsu, Elisabeth

Publication date:

2017

Permanent link:

https://doi.org/10.3929/ethz-b-000488877

Rights / license:

In Copyright - Non-Commercial Use Permitted

Originally published in:

Asiatische Studien - Études Asiatiques 71(1), https://doi.org/10.1515/asia-2016-0028 


\title{
Franz K. Huber, Caroline S. Weckerle and Elisabeth Hsu* The Shuhi House between Reformist China and Revivalist Tibet
}

DOI 10.1515/asia-2016-0028

\begin{abstract}
The Shuhi of Muli County, Sichuan province, inhabit the TibetanChinese borderlands. In this paper, we focus on Shuhi kinship practices that accord the house the importance it appears to have for the Shuhi themselves. We demonstrate that the Shuhi engage in kinship practices that are 'hearthoriented' (Hsu 1998b: 67-99) in a dynamic process affected by the current political economic changes in reformist China and religious revivalism in Tibet. The 'hearth-oriented' kinship practices we discuss include issues of who among the offspring continues to live in the house of their parents, how places of worship in a house are oriented in relation to the physical environment and the divine landscape, and how practices regarding the naming of houses are changing from deictics of place to lineage and family names. Based on empirical data, gathered between 1996-2011, we show that there are significant differences in all practices, which reflect a Tibetan-Chinese gradient along the north-south axis of Shuhi settlements. But there are also striking continuities.
\end{abstract}

Keywords: house, kinship, cognatic, hearth-oriented, house architecture, house names, Southwest China

The Shuhi, also known as Xumi, Shumu or Shimi, are a small ethnic group who inhabit Shuiluo Township on the Shuiluo River gorge, which is one of several north-south running tributaries of the Golden Sand River (the upper reaches of

*Corresponding author: Elisabeth Hsu, University of Oxford, Institute of Social and Cultural Anthropology, 51/53 Banbury Road, Oxford, OX2 6PE, Great Britain and Nothern Ireland.

E-mail: elisabeth.hsu@anthro.ox.ac.uk

Franz K. Huber, ETH Zürich, Institute for Environmental Decisions, Sonneggstrasse 33, 8092 Zurich, Switzerland. E-mail: huber@ethnobot.ch http://orcid.org/0000-0002-4632-8939

Caroline S. Weckerle, University of Zürich, Department of Systematic and Evolutionary Botany, Zollikerstrasse 107, 8008 Zürich, Switzerland. E-mail: caroline.weckerle@systbot.uzh.ch 
the Yangtze River). The Shuhi speak a distinct language, Shixing, ${ }^{1}$ but in the People's Republic of China (PRC) have been officially classified as Tibetan (Chin.: Zangzu). ${ }^{2}$ They numbered about 2500 people in the census of 1990. Together with about 10,000 Kham-speakers who call themselves Bo, also known as Gami Tibetans or Xiami, 22,000 Premi-speakers (in Yunnan known as Pumi) and some 2000 Liru and Lamuzi (also known as Namuyi), they constituted the about 35,000 'Tibetans' of Muli County, which thus became a Tibetan Autonomous County. ${ }^{3}$

In 2005 the Shuhi numbered fewer than 1,500 people who all lived in Shuiluo Township. ${ }^{4}$ This decrease in numbers arose not only from ethnic reclassifications of the same people (see below), but also testifies to radical social changes. The Dengist economic reforms affected people in many ways, and most conspicuously gave rise to intensified prospecting for gold and silver in the Shuiluo river. ${ }^{5}$ Poor peasant labourers, mostly from Hunan province, and capable, often ruthless entrepreneurs from the region of Western Sichuan joined forces. In the summers of the early 1990s the labourers were some several hundred people who camped in tents of plastic planks, well segregated from the local population, on the sand and gravel of the river banks. In the late 1990s, when no road had yet been built to the administrative centre of Shuiluo Township, the gold diggers made use of the roads constructed by the government's Forest Bureau that in the early 1990s had enabled logging companies to rid Muli of its vast primary forests within less than a decade. After that industry was brought to a halt with a complete logging ban following disastrous flooding downstream, the same entrepreneurs prospected for new deposits. In the Shuiluo valley the frenzy for gold digging reached a peak in the 2000s.

To be sure, the local population of Shuiluo had been taking part in gold prospecting activities for decades. Before the Chinese Communist takeover households were obliged to deliver a certain amount of gold and other resources to the Gelugpa Buddhist monastery in Muli, which put pressure on labour and

1 Sino-Tibetan according to Sun 1990, who consciously chose a broad and more inclusive term; Tibeto-Burman according to Chirkova et al. 2016.

2 We note the region's strong orientation towards Tibet already in the 1950s, in contrast to the gazetteers of Late Imperial China where the Tibeto-Burman speaking ethnic groups were subsumed among the „Western barbarians“ (Xifan or Hsi fan) who were considered distinct from the Tibetans in the West and the Yi /Nuosu in the East (Hsu 1998a). See also Harrell 2001: 197-215.

3 Wellens 2010: 54.

4 Weckerle et al. 2006.

5 Huber et al. 2014. 
agricultural production and at times caused famines in the villages. After 1970 state-run gold companies entered Shuiluo valley and after 1994 private companies were permitted to do so. Once the road to Shuiluo Township was built in 2001, diggers and washers entered the valley in higher and higher numbers, and gold furnished Shuiluo Township with a thriving local economy. In the early 2010s locals could engage in gold washing themselves and work on abandoned sites or as employees for a company or make themselves to employers of labourers. Locals were furthermore drawn into the gold washing industry by providing transportation services, supplying workers with timber, fuel or food. The data on the Shuhi house presented below need to be seen against this backdrop of drastic social change.

\section{The Shuhi house in perspective}

The Shuhi are considered patrilineal, like the neighbouring Tibetans and other Tibeto-Burman groups. ${ }^{6}$ However, the common classification into a patrilineal kinship system underplays co-existent kinship practices that do not fit the scheme. By foregrounding the house (Shixing: zhahong) as a material and conceptual entity that structures social organisation, we aim to account for a perception of kinship practices that became apparent through observing and recording both their sayings and doings. This cannot entirely replace but will complement research undertaken in the anthropology of kinship into patrilineal, matrilineal, bilineal or cognatic kinship systems. ${ }^{7}$

Kinship practices in the Shuhi house currently co-exist in hybrid form. In this paper we make an effort to appreciate them in the light of two supraregional primarily socio-political (Chinese) and religious (Tibetan) regimes. In another paper, we discuss the Shuhi house in the light of supra-regional agroarchaeological cultural complexes derived from different stone-age technologies of cooking. ${ }^{8}$ All these supra-regional influence spheres affect the Shuhi also indirectly, in interaction with other local peoples who inhabit the Shuiluo

6 Weckerle 1997.

$7 \mathrm{Hsu}$ 1998b formulated this view in the mid-1990s, in an attempt to put the conundrum of patrilineal Naxi versus matrilineal Na, into comparative perspective. See also Wellens (2006) on the Premi, and more recent Oslo-based research on the Qiang.

8 See Hsu, Huber and Weckerle, this volume, on the Shuhi as a rice-boiling people who have cultivated a disposition in daily life, annual rituals and kinship practices to keep in place and condense the ever elusive life substances (comparable to qi or mana) within house and hamlet. 
valley: the Gami Tibetans in the north of the valley, the Naxi in the south and a southern side valley, the $\mathrm{Na}$ (who called themselves Mengguzu) with one village in the centre of the valley, and the Premi who controlled the upper cooler rim of the valley through which threaded the long-distance tracks of the 'horse tea road' (as distinct, according to some, from the 'southern silk road'). Clearly, the Shuhi are part of a complex cultural fabric with its own internal dynamics.

By discussing the Shuhi house in view of the multiple regimes outlined above, we construct a layered description of Shuhi kinship, daily life routines and ritual practice. We do not consider it possible to dissect contemporary cultural "systems" into "elements" that are culturally "pure". Rather, we consider contemporary Shuhi kinship practices to have evolved dynamically in local, regional and supra-regional interactions, and led to the practices currently observed. In full awareness that what we document today is evidence of fleeting, fragmented and fluid processes, testifying to a complex history, we posit that it is possible to single out some kinship practices as characteristic of certain time periods and/or societal dynamics. In particular, we wish to test to what extent the house as perceived by the Shuhi themselves is central to Shuhi social organisation, albeit modified by a) the social and political economic developments in the contemporary PRC and b) the Tibetan religious revival.

All houses in Shuiluo Township are eye-catching architectural structures. Newly built houses often are $10 \mathrm{~m}$ in length and $12 \mathrm{~m}$ in width, or more, while old houses are significantly smaller. Shuhi houses are built like Tibetan houses, and have three storeys. The ground floor is for the cattle - in 2005, Shuhi households possessed about six cows and oxen, four horses/mules, seven pigs and eighteen goats. The cattle provide the heating for the first floor which is the human space, the hearth (Shixing: gú) being positioned opposite the entrance in the one spacious room for eating, living and sleeping. Finally, the flat roof formed an open space in which grains are dried, threshed, winnowed and stored and on which daily morning rituals are performed. This tripartite structure of the house is marked by a verticality typical of Tibetan cultures and cosmologies ${ }^{9}$ and reproduces in stone, mortar and wood, the Buddhist pantheon that puts the sturdy animal heat lowest, the ethereal gods highest and humans in between.

9 Blondeau/Steinkeller 1996. 
The house is thus both a conceptual and a physical, tangible, material structure $^{10}$ and fieldwork has reconfirmed that it clearly does shape social relations and relatedness in everyday life. Rather than calling the house a kinship 'category' or a 'metaphor', it is perhaps best approximated as a 'toolsign'11 for it has both powers of the imagination and of tangible matter for generating relatedness and kinship ('kinning' in Howell's ${ }^{12}$ words).

We will argue that the Shuhi house remains an important 'tool-sign' for 'kinning' in the twenty-first century, ${ }^{13}$ but this cannot be done without accounting for recent social changes. We consider them to have been triggered by 1) the reformist Chinese socialist state apparatus that today exerts an undeniable socio-political presence in the valley and brings with it Han values, customs, language and regulations regarding property and taxation, marriage and inheritance, ${ }^{14}$ and 2) revivalist Gelugpa Buddhist activities which cannot reinstate the Tibetan theocratic state but nevertheless pervade religious and daily life. ${ }^{15}$

\section{A note on fieldwork}

A reconnaissance trip in 1992, organized with the Sichuan mountaineering association to the three sacred mountains Chenrezig, Jampayang and Chenadorje, of around $6000 \mathrm{~m}$ above sea level, made Hsu aware of the Shuiluo valley. The valley was then so remote as to be the only large river gorge system in Sichuan Province into which no road had been built. Hsu thereupon organised weekly fieldwork-preparatory seminars in social anthropology at the University of Zurich, which over the period of three years examined basic aspects of the local Premi dialect (with an exile monk from the Shuiluo valley), the Chinese literatures on the ethnic fabric of Southwest China, and social anthropological literatures on 'house-based societies' and 'cultures of relatedness'. 16

10 Carsten 2000.

11 Novellino 2009.

12 Howell 2003a.

13 For details on these kinning processes, see Weckerle 1997 and Hsu, Huber \& Weckerle, this volume.

14 Huber 2013.

15 Wellens 2006, 2010.

16 Summarised in Hsu 1998b. 
In spring 1996, finally, four student group members undertook coordinated fieldwork in the Shuiluo valley for six weeks, which centred on activities in and around the house from different (sub-)disciplinary perspectives: Roland Naef ${ }^{17}$ who was interested in gender, studied the Menggu (Na/Mosuo) in Lianmu village, Markus Schiesser ${ }^{18}$ did visual anthropology with the Premi in Siweng village, Beatrix Nüscheler (Chinese studies) worked with the Naxi in Guni village and Caroline Weckerle ${ }^{19}$ studied the ethnobotany of the Shuhi in Lanman village. Each Swiss student was paired with a Chinese (from the University of Southwest China) but communication was difficult. None spoke a local language, and only one of the Swiss students was fluent in Chinese.

The research presented here has more robustness. Weckerle and Huber made many fieldtrips to Shuiluo Township and also to other parts of Southwest China between 2004-2011, each ranging between three weeks to three months (with the support of the Kunming Institute of Botany, Chinese Academy of Sciences). They built up a small but vibrant student group in ethnobotany at the University of Zurich, which resulted in over fifteen published and unpublished studies, including Huber's ${ }^{20}$ doctorate. The data presented here was collected mainly in 2004 and 2005.

The Shuhi house is here in focus following Hsu's ${ }^{21}$ suggestion to treat the house as an analytic entity for kinship reckoning, defined in the region by a tension between locally perceived 'hearth-oriented' and 'alliance-oriented' kinship practices. Inspired by the work of Carsten and Hugh-Jones, ${ }^{22}$ who reformulated Levi-Strauss' writings on house-based societies in a way that takes the house as a heuristic device, Hsu suggested to widen the remit of discussions regarding kinship, which was locked into a plotting of patrilineality versus matrilineality in the region of Southwest China, to consider 'emic concepts', or what we call today 'tool-signs', analytically relevant. She proposed to accord these emic concepts, like the 'house' (Shixing: zhahong), an analytic importance for making sense of kinship. She noted that some practices were 'hearthoriented', i. e. practices that were meant to strengthen the hearth/house community (some of which an etic perspective would consider indexical of 'cognatic'

17 Naef 1998.

18 Schiesser 2000.

19 Weckerle 1997.

20 Huber 2013.

$21 \mathrm{Hsu}$ 1998b.

22 Carsten and Hugh-Jones 1995. 
or 'bilateral' kinship), while other kinship practices drew on the emic concept of e.g. 'bone and flesh' (when speaking from an etic viewpoint of 'exogamous' marriage practices). Nancy Levine, ${ }^{23}$ in particular, had written very lucidly about the local understandings of 'bone and flesh' as principles of kinship. 'Hearthoriented' kinship practices seemed to Hsu to point in direction of what etically might be called a 'substratum of cognatic kinship' (although she avoided this terminology), and not necessarily matrilineality. Ultimately, Hsu's aim was to introduce into the anthropological discussion of kinship the terminology that the locals used and accord it the status of an analytic principle that would complement - and critically comment on - the usual anthropological kinship terminology that is 'etic'. Just like in the 1970s a focus on the 'emic' concept of 'illness' had opened a new field of study, that of medical anthropology, which critically complemented the biomedical discourse on the 'etic' assessment of 'disease', Hsu wished to enrich the discussion of kinship with what we here call locally derived 'tool-signs' of kinning. This article aims to make sense of the longrecorded but as yet unpublished data of Shuhi kinship reckoning with a focus on 'hearth-oriented' kinship practices.

\section{Hearth-oriented kinship practices}

The data presented in this article concern kinship practices not usually discussed in kinship studies and rarely recorded as systematically as presented here. This is because we work with the local concept of the 'house' (Shixing: zhahong) as a concept of importance to Shuhi kinship, and this entailed developing fieldwork-specific terminologies in the field. For instance, when practices concerning the offspring who would continue to live in the house were investigated, the fieldworkers Weckerle and Huber, alongside Naef and Schiesser, worked with the concept of a 'house line' and its continuation. They spoke of houses being 'taken over' or 'inherited'. These terms were not derived from the vocabulary of the locals, nor may they always adequately describe the kinship practices implied. For instance, 'inheritance' presupposes a concept of ownership that most ethnic groups in the region did not seem to have before the 1950s: whoever 'inherits' a house is not necessarily obliged to continue to reside in it. Nevertheless, such concepts proved useful in the field as fieldworkers felt they could make themselves understood. Thus, the 'take-over' of a house involved

23 Levine 1988. 
'taking responsibility' for observing ritual prerogatives of the house such as making offerings at the hearth, as the Shuhi reconfirmed.

The three practices discussed in what follows we consider 'hearth-oriented' kinship practices. ${ }^{24}$ These practices were not called 'hearth-oriented' by the Shuhi themselves but they were identified by observing and reflecting over what the Shuhi did. The first hearth-oriented kinship practice concerns the question of who among the offspring would stay resident in the house, a concern which is likely to have been motivated by a concept of a ritual obligation to keep it alive. Houses often have ritual prerogative and are ranked, which the house inhabitants must observe. ${ }^{25}$ The Shuhi did not explicitly say they had to keep the 'house' alive but what they did, such as the making of daily offerings at the hearth, is best interpreted as offerings to the living principle of the house. ${ }^{26}$

Second, practices regarding the orientation in which the houses are built in relation to the environment are not usually discussed in kinship studies. We investigated them primarily with an interest to identifying the orientation of the house altars and other places of worship in the house. Accordingly, we propose to treat offerings at the hearth as an aspect of hearth-oriented kinship practices, which emphasize the importance of place. Kinship studies have much emphasized the importance of place, not least when discussing 'residence'; in the current study we explore the extent to which venerations of the hearth may be considered distinctive of a 'hearth-oriented' kinship practice.

Third, the fact that Shuhi houses and fields had names is noteworthy. Again, this is not uncommon worldwide; it is often explained in terms of deictics. However, we propose to treat house names that accord the place itself more importance than the names of the people dwelling in it, as an aspect of hearth-oriented kinship practices, in line with research that considers practices relating to the naming of houses part of the repertoire of kinship studies.

Our discussion attends first to variations in hearth-oriented practices affected by Han Chinese kinship practices and then we discuss variations of 'hearth-oriented kinship practices' that hybridisation with Tibetan religious practices might best explain. In each case we discuss variations observed in five of the around eight Shuhi villages (in the sense of natural villages, as opposed to Administrative Villages) in Shuiluo Township. Xiwa was half a day's walk, and Jiassa and Lanman some two hour's walk away north of the

24 Hsu 1998b.

25 Howell 1995, 2003b.

26 Detailed in Hsu, Huber and Weckerle, this volume. See also Wellens 2006: 149, 155. 
township's administrative centre, Pingweng was situated just there, and Mianbang was half a day's walk to the south. The entire north-south expansion of the Shuhi ethnic group ranges from Xiwa to Mianbang. Weckerle and Huber visited nine houses in Xiwa, six in Jiassa, seventeen in Lanman, eleven in Pingweng, and seven in Mianbang. They also visited houses in other villages (e. g. Liangbao) but too few to report on here.

The township buildings of the government are situated between two adjoining villages, namely Pingweng, inhabited mostly by Shuhi, and Lianmu, inhabited by the Menggu (Mosuo/Na). The new government administrators, who built and lived in brick buildings, were often Tibetans from elsewhere in Muli County stationed there for three years, sometimes more. They were cadres who brought with them Han values and policies intended to make the local population modern and socialist. Among the administrators with whom Hsu spoke extensively in 1992, and again in 2003, the Stalinist conviction prevailed that eventually distinctive cultural traits would disappear. They spoke of an 'assimilation' of these peripheral peoples into the modern nation-state. ${ }^{27}$

\section{Residence patterns for keeping the house alive}

If one compares the Shuhi living in Pingweng, near the administrative centre of the township, and in Lanman, which was two hours walk away, in regard of who continues the house line the differences are striking. In Pingweng the house was inherited in 13 out of the 20 recorded cases by the eldest son, whereas in Lanman it was handed over to the eldest child. Regardless of its gender the oldest child continued living in the house in 29 out of 31 recorded cases; 14 were male, 15 were female (see Table 1).

In Lanman Village, to which Weckerle and Huber had closest ties, they visited 17 houses (including all 15 houses of one hamlet) on several occasions. They found that the pattern of handing on the house to the oldest child, regardless of whether the child was a son or daughter, had been constant for the last three generations. In two houses of Lanman the oldest son, rather than the oldest child, continued living in the house. In one of those the head of house was an official in the township's administration and deliberately adhered to the Han Chinese custom of a patrilineal inheritance.

In Pingweng the survey included eleven houses inhabited by Shuhi, and we recorded and discussed twenty 'hand-overs' of the house in the last three

27 However, consider Harrell 2001. 
Table 1: House hand-overs. Villages are listed in north to south direction.

\begin{tabular}{lcccr}
\hline & Generation G+1 & Generation 0 & Generation G-1 & total \\
\hline Xiwa (houses visited: 9) & & & & \\
\hline Total "house hand-overs": 17 & 4 & & & \\
Male & 0 & 1 & 6 & 14 \\
Female & & & & \\
Analysed "house hand-overs": 11 & 0 & 2 & 4 & 6 \\
Male, oldest child & 0 & 1 & 2 & 3 \\
Female, oldest child & 0 & 0 & 2 & 2 \\
Male, not oldest child & 0 & 0 & 0 & 0 \\
Female, not oldest child & & & &
\end{tabular}

Jiassa (houses visited: 6)

Total "house hand-overs": 10

Male

Female

$\begin{array}{llll}1 & 3 & 2 & 6\end{array}$

2

0

24

Analysed "house hand-overs": 8

Male, oldest child

Female, oldest child

\begin{tabular}{llll}
0 & 2 & 2 & 4 \\
2 & 0 & 1 & 3 \\
0 & 1 & 0 & 1 \\
0 & 0 & 0 & 0 \\
\hline
\end{tabular}

Male, not oldest child

Female, not oldest child

Lanman (houses visited: 17)

Total "house hand-overs": 39

Male

Female

5

5

Analysed "house hand-overs": 31

Male, oldest child

Female, oldest child

Male, not oldest child

Female, not oldest child

Pingweng (houses visited: 11)

Total "house hand-overs": 25

Male

Female

5

2

8

2

$8 \quad 21$

Analysed "house hand-overs": 20

Male, oldest child

Female, oldest child

Male, not oldest child

\begin{tabular}{rrrr}
0 & 3 & 4 & 7 \\
1 & 1 & 0 & 2 \\
2 & 4 & 4 & 10 \\
\hline
\end{tabular}


Table 1: (continued)

\begin{tabular}{lrrrr}
\hline & Generation G+1 & Generation 0 & Generation G-1 & total \\
\hline Female, not oldest child & 0 & 1 & 0 & 1 \\
\hline Mianbang (houses visited: 7) & & & & \\
\hline Total "house hand-overs": 18 & 3 & & 5 & 12 \\
Male & 2 & 4 & 3 & 6 \\
Female & & 1 & & \\
Analysed "house hand-overs": 14 & 2 & & 2 & 6 \\
Male, oldest child & 1 & 2 & 1 & 2 \\
Female, oldest child & 0 & 0 & 3 & 5 \\
Male, not oldest child & 0 & 2 & 1 & 1 \\
Female, not oldest child & & 0 & & \\
\hline
\end{tabular}

generations. In seven cases, a boy was first born, in thirteen a girl, but the oldest child stayed in the house only in nine out of twenty cases, i. e. in all cases where a boy was the first born, but only in two where a girl was the first born. Significantly, the house went to a son, as it does in a patrilineal kinship system, regardless of whether or not he was the oldest child, namely in seventeen out of twenty cases (only in one case a girl who was not a first born stayed in the house). It is striking that in generation G-1 (where the ages vary between 10 and 26 years), the oldest son continued living in the house in all eight cases, even though in half of them (four out of eight) a daughter was the oldest child. In summary, close to the centre of the township, in the Shuhi houses of Pingweng, patrilineal Han practices were favoured. By contrast, the Lanman Shuhi, where the house goes to the eldest regardless of gender, may be interpreted as continuing to adhere to hearth-oriented kinship practices.

As already said, the township's administrative centre was situated between Pingweng and Lianmu. Lianmu was mostly inhabited by people who presented themselves to Naef as Menggu. They said of themselves that they were patrilineal, well aware that the Yongning Mosuo on Lake Lugu, whom they also considered Menggu, were classified as matrilineal. However, Naef found that the house went to 36 men and 31 women, out of the total of 67 cases he recorded. ${ }^{28}$ Among them were cases where two daughters continued to live in the house in a polygynic marriage (i. e. a single husband for two sisters married into a house), instead of the house being given to their first-born brother (which points to flexibility and sensitivity to the situational, as is characteristic of cognatic

28 Naef 1998: 50. 
kinship systems). It is furthermore worth noting that Naef was told that in Lianmu the eldest son would inherit the house, when the data he recorded demonstrates that in most cases the Lianmu Menggu continued to adhere to the practice of ensuring that the house remained inhabited by the first-born child, regardless of gender. Evidently there was a tension between a proclaimed kinship system, patrilineality (which was also that of the dominant group in the township), and recorded kinship practices. It is well-known among fieldworkers that there is a tension between what people say and what they do, particularly in situations of drastic socio-political change.

There are striking statistics of the Yongning Mosuo on the shores of Lake Lugu, which point to a similar tension between a proclaimed kinship system, in that case matrilineality, and hearth-oriented kinship practices. However, while all fieldworkers in the Shuiluo valley worked with a concept of a 'house line' and its continuation, Shih did not systematically research this. Rather, his focus was on descent, residence patterns of co-habitation and household divisions. $^{29}$

Shih does however comment on the gender ratios regarding the 'head of house' (dabu) among the Yongning Mosuo, noting that they were well-balanced: "The statistics of three village surveys in 1956 [in the Yongning basin] point to a fairly equal distribution between male and female dabu [heads of houses]: 38 out of 88,44 out of 86 and 15 out of 27 houses had male dabu." Knoedel ${ }^{30}$ reported on these three surveys in percentiles: 43\%, 51\% and 55\%. Shih and Knoedel provided additional data to argue that the Yongning Mosuo were matrilineal, but $\mathrm{Hsu}^{31}$ pondered over the finding that the gender ratio between the male and female $d a b u$ was so equal. Although she remembered that headship in a matrilineal system often is male, ${ }^{32}$ and that the above findings would not weaken Shih's argument that the Yongning Mosuo are matrilineal, ruminations over local kinship terms ${ }^{33}$ drew her to an explanation that promised to have historical traction. ${ }^{34}$ This was to postulate that the 'house' was a locally perceived material and conceptual entity for creating 'cultures of relatedness' and kinship.

29 Shih 2010: 192-206. Among several excellent ethnographies, the arguments of Shih 1993, 2010 and Knoedel 1995 drew on substantial quantitative data regarding kinship practices.

30 Knoedel 1995: 129.

31 Hsu 1998b: 79-80.

32 Schneider 1961.

33 reminiscent of Schneider 1984.

34 Consider Rowlands/Fuller 2009. On the history of culinary technology, which in Hsu, Huber and Weckerle, this volume, is referred to for explaining continuities to tropical Southeast Asia of hearth-oriented kinship practices. 
The new data from the Shuiluo valley are much in line with the above census data on Lake Lugu. If one considers both the becoming of a dabu and the taking responsibility for the continuation of the 'house line' as a hearthoriented kinship practice, one can observe that these were endorsed in a genderblind way. This was so among the 'matrilineal' Yongning Mosuo, the 'patrilineal' Lanman Shuhi and the 'patrilineal' Lianmu Menggu. In other words, whether or not they were 'matri-' or 'patrilineal' did not really matter. Among all these ethnic groups about whom we have numerical data, we can thus deduce that the house is best conceived of as a 'tool-sign' for 'kinning'.

It would be wrong to make Han patrilineality alone responsible for variations of Shuhi practices regarding the continuation of hearth and house. If one compares Shuhi practices in this regard, along said north-south axis, it is evident that supra-regional Tibetan practices that point in direction of patrilineality matter as well. The village Xiwa in the north is geographically close to the Gami Tibetans of Dulu and Galuo, and over the short period between 2005 and 2010 a significant reclassification in ethnic identity took place in Xiwa. While in 2005, 22 out of 25 houses in Xiwa referred to themselves as Shuhi, in 2010 the situation changed completely, and the majority referred to themselves as Gami. Exceptions were the elder people. This shift was accompanied by a transition in language preferences from Shixing to Gami Tibetan, with only older people still using Shixing during daily conversation. ${ }^{35}$ The Jiassa Shuhi showed similar trends towards a Gami Tibetan identity, but much less than the Shuhi in Xiwa; geographically Jiassa lay closer to Lanman than to Xiwa. They also seemed more conservative in their kinship practices. In the six houses visited, usually the oldest child stayed resident in the house (but this small sample size forbids meaningful interpretation).

In general, the Lanman Shuhi were least affected by external pressure and kept endorsing hearth-oriented Shuhi kinship practices. For instance, only the Lanman Shuhi had ancestral stone seats that were named after their old houses. ${ }^{36}$ In Lanman no changes regarding ethnicity and language were observed. The Pingweng Shuhi, as already mentioned, were proximate to the political centre of Shuiluo Township, and their hearth-oriented practices regarding the continuation of the 'house line' were strongly transformed by the nearby Han Chinese presence.

35 Büeler 2010.

36 For more detail, see Hsu, Huber and Weckerle, this volume. 
In Mianbang, finally, the southern-most village, a significant part of interviewees had a strong Han Chinese background (e. g. Han-Chinese marriage into the village, teacher or official at the administrative centre of the township), and the large proportion of hand-overs to sons is thus best interpreted in that light.

There is little doubt that both the patrilineal Han Chinese practices, which were considered more civilized and modern and Tibetan practices, which villagers often adopted in a quest of cultural identity, motivated a change away from given Shuhi practices. The recorded patterns of keeping houses alive by ensuring that the first-born kept residing in the house constitute only one small aspect of an entire kinship system. It would be misleading to suggest that a kinship system as whole was, in the Stalinist sense, 'assimilated' to the Han Chinese or Tibetan one and thereby exterminated. Kinship practices are best understood as part of a dynamic field marked by tensions between the temporally-situated socio-political trends, historical and more locality-specific socio-cultural and ecologically-motivated patterns. Clearly, the hearthoriented kinship practices of continuing the 'house line' were most pronounced among the Lanman Shuhi.

\section{The hearth's orientation towards the mountain}

It is well-known that houses of worship are built with specific orientations such that the devout can perform their prayer accordingly. The Shuhi house, as all houses in Shuiluo valley, were not only dwellings for the living but living entities themselves. ${ }^{37}$ Furthermore, they provided shelter for principles of the divine, be it zhambala by the hearth, the ancestors or the klu (naga, snakes/ dragons), who dwelt in a water source nearby but also can be present in the big copper water container in the kitchen of the houses.

We aimed to identify whether the orientation in which the various places of worship in a Shuhi house were built would reveal which gods the house's inhabitants venerated. In full awareness that Shuhi villages are built in clusters not unrelated to each other, and that terrain can pose limitations, we viewed each house as an independent structure. Orientations were measured in the visited houses of the above five Shuhi villages in Shuiluo Township (Table 2). In order to make sense of the data, orientations of the house of each village were classified as either 'highly consistent' in orientation (standard deviation of $\pm 20^{\circ}$

37 Hsu 1998b; Yang 1998; Wellens 2006. 


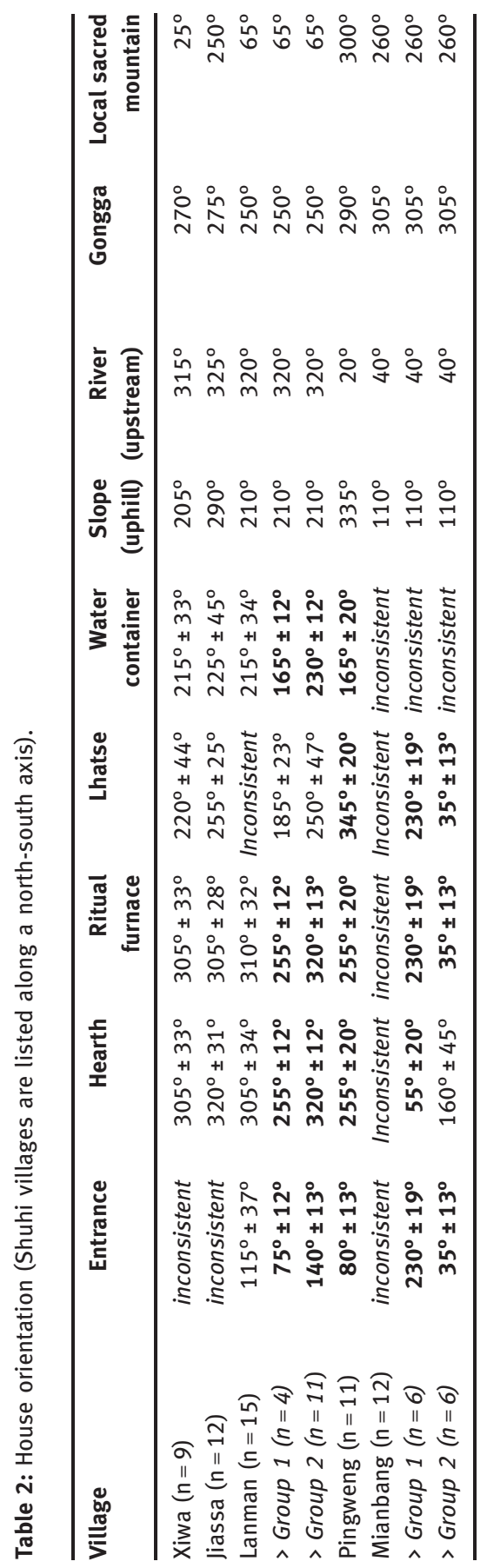


or smaller (indicated in bold), or 'consistent' (with a standard deviation of between $\pm 21^{\circ}$ to $\pm 50^{\circ}$ ) or 'inconsistent' (when standard deviations exceeded $\pm 50^{\circ}$ ). Furthermore, any architectural feature of the house (e.g. house door, ritual furnace on roof top) built in a highly consistent orientation towards an environmental feature was rated as being of a higher cultural importance than inconsistent orientations.

This quantitative research yielded some interesting but tentative qualitative results. For instance, in most Shuhi villages - except for Mianbang - the entrance door was found to be oriented towards the East, such that the hearth was positioned on the (North-) West. This paralleled, incidentally, the ideal house orientations among the Yongning Mosuo $^{38}$ and among the Bustling Town Premi. ${ }^{39}$ Further research has to answer why in Mianbang, and also in Lanman the aggregated data showed low consistency. Only the division of the data on the houses into two sub-groups yielded a clear picture of consistency within each subgroup (see Table 2: for Mianbang and Lanman, the directions are presented for all houses aggregated as well as divided into two subgroups, respectively). Particularly in Mianbang, one subgroup tended to have the entrance, the ritual furnace and lhatse most likely towards the local sacred mountain.

In addition, we found that not merely the orientation of the hearth inside the house mattered but also that of the ritual burner on the roof. The lhatse on the roof consistently was oriented towards the West. To make sense of this finding, one has to know that the region's most sacred mountains, which the people simply called gongga (Chinese rendering of the Tibetan konka) are located in the western parts of the Shuiluo valley. The three sacred mountains Chenrezig, Jampayang and Chenadorje are conspicuous in shape and height, and all peoples in the valley venerated them.

Noteworthy is that the data suggested that it was not the nearby visible local and protective mountain of the village that was being worshipped most intensely, but the faraway gongga mountains. In none of the villages could one see one of the three sacred peaks but people knew that they were there in the west. The mountain gods had become part of the Buddhist pantheon, but at the same time these mountains in themselves were divine powers, as mountains tend to be also among the Chinese, in the Pacific, in the Americas and elsewhere.

Throughout the valley people engaged daily in practices of venerating the house, the ancestors and/or the gods, both by the hearth and on the open roof

38 Shih 2010: 214.

39 Wellens 2010: 124. 
top. ${ }^{40}$ A strong influence of Tibetan Buddhism was observed especially in the use of dried incense plants (i. e. Cupressus, Juniperus and Rhododendron species). As a consequence there was very little variation between the villages regarding dried incense plants, while distinct local characteristics were observed in the use of other ritual plant categories, for instance, in the use of fresh incense plants. In the northern Shuhi village of Xiwa and Jiassa pine tree was of greatest importance for worshipping during the daily morning ritual, while in Pingweng, but also Lanman, and the southern village of Mianbang Pistacia weinmanniifolia was used prevalently. Mianbang was the only village, in which also Osyris quadripartita and Cornus oblonga were used on a regular basis. So, once again, variations in ritual practice could be observed along a north-south axis, presumably due to interactions with the Gami Tibetans in the north and the Naxi in the south. ${ }^{41}$ As there is little ecological difference between the villages, this finding supports the conclusion of Weckerle et al., ${ }^{42}$ that the use of ritual plants is predominantly based on a cultural rationale, while other plant use categories depend more on ecological and accessibility factors.

\section{House names}

Shuhi houses, like those of other peoples' in the Shuiluo valley, were built to last for decades as three-storied wooden frame constructions surrounded and supported by massive stone walls. They often had names that referred to the location of the house. We suggest considering this naming of the houses according to the place into which they were built a hearth-oriented kinship practice, even if one may object that it merely reflects a deictic convention and the pragmatics of referring to the house as a locality. Wellens describes the name of the Premi house to be usually the name of the one who built the house and therefore to be a straightforward reference to the founder of the house. ${ }^{43}$ This practice is also observed among the Shuhi, but particularly the names of older Shuhi houses downplayed the importance of the human founder of the house. Instead, place was foregrounded, and with it, we hypothesize, place making as a mode of creating relatedness.

\footnotetext{
$40 \mathrm{Hsu}$, Huber and Weckerle, this volume.

41 Büeler 2010.

42 Weckerle et al. 2006.

43 Wellens 2010: 114.
} 
As already said, house names were often deictics: up there, down below, on the very top, on the side, etc. Occasionally the house name would be taken over by new inhabitants of a house after the previous inhabitants had died out. This was if the inhabitants had been relatives and the new inhabitants felt they could continue to worship the same deities and ancestors of the house. Examples of the kind include in Lanman a house that went extinct, whereupon the grandmother's sister and her husband moved into the house, kept the old house name and continued to worship its ancestors. Yet if the people who were moving in were not close relatives, they would worship their own ancestors. In some cases when the new inhabitants were not related to the old family, they could either keep the old house name or get a new one for the old house. On the other hand, if a house was rebuilt at a new location, the old house name would be transferred to the new house.

Among the nine houses visited in the northern-most Shuhi village Xiwa, four house names related to the locality, two to a person, two consisted of two names (the first for a locality and the second for a person), and one had another meaning. Similarly, in Jiassa, houses were named predominantly after localities, not people (4:1). In Lanman, of the seventeen house names recorded, seven referred to a locality, five of which were known to be old houses, and seven to a person, three of which were identified as an old house. In five of the above fourteen cases, however, it was uncertain whether the house was old or new. Of the three known new houses in Lanman, two were called "New House" in another local language and one was named after its male founder; none referred to a locality. In Pingweng, of the eleven houses visited, six were old ones and five new. Of the old houses, the one name that was recorded referred to a locality; the house names of the five other old houses could not be identified. Among the five new houses, two were called "New House", one was named after its founder, one referred to a locality and one had another name. In Mianbang, by contrast, all seven houses (four old, three new) had names with other meanings (see Tables 3 and 4).

Table 3: Shuhi house names divided into 4 main categories of house names.

\begin{tabular}{lrrrrr}
\hline Village & $\begin{array}{r}\text { Xiwa } \\
(\mathrm{n}=9)\end{array}$ & $\begin{array}{r}\text { Jiassa } \\
(\mathrm{n}=5)\end{array}$ & $\begin{array}{r}\text { Lanman } \\
(\mathrm{n}=17)\end{array}$ & $\begin{array}{r}\text { Pingweng } \\
(\mathrm{n}=11)\end{array}$ & $\begin{array}{r}\text { Mianbang } \\
(\mathrm{n}=7)\end{array}$ \\
\hline Person name & 2 & 1 & 7 & 1 & 0 \\
Locality name & 4 & 4 & 7 & 2 & 0 \\
Person\&Locality & 2 & 0 & 0 & 0 & 0 \\
"New house" & 0 & 0 & 2 & 2 & 0 \\
Other name & 1 & 0 & 1 & 6 & 7 \\
\hline
\end{tabular}


Table 4: Coded Shuhi house names and age of each house.

\begin{tabular}{llllll}
\hline House no. & Xiwa & Jiassa & Lanman & Pingweng & Mianbang \\
\hline 1 & $\mathrm{Fm}(\mathrm{X})+\mathrm{L}(\mathrm{G})+\mathrm{O}(\mathrm{G})-\mathrm{B}$ & $\mathrm{L}(\mathrm{X})-\mathrm{A}$ & $\mathrm{Ld}(\mathrm{X})-\mathrm{A}$ & $\mathrm{NH}(\mathrm{P})-\mathrm{B}$ & $\mathrm{nn}(\mathrm{Nn})-\mathrm{A}$ \\
2 & $\mathrm{Lf}(\mathrm{G})-\mathrm{B}$ & $\mathrm{L}(\mathrm{X})-\mathrm{B}$ & $\mathrm{Ld}(\mathrm{X})-\mathrm{A}$ & $\mathrm{NH}(\mathrm{P})-\mathrm{B}$ & $\mathrm{nn}(\mathrm{Nn})-\mathrm{A}$ \\
3 & $\mathrm{Lf}(\mathrm{G})+\mathrm{Ff}(\mathrm{G})-\mathrm{B}$ & $\mathrm{Fm}(\mathrm{Nn})-\mathrm{A}$ & $\mathrm{O}(\mathrm{X})-\mathrm{A}$ & $\mathrm{O}(\mathrm{Nn})-\mathrm{B}$ & $\mathrm{nn}(\mathrm{Nn})-\mathrm{A}$ \\
4 & $\mathrm{O}(\mathrm{C})-\mathrm{A}$ & $\mathrm{L}(\mathrm{Nn})-\mathrm{B}$ & $\mathrm{NH}(\mathrm{P})-\mathrm{B}$ & $\mathrm{Ld}(\mathrm{X})-\mathrm{B}$ & $\mathrm{nn}(\mathrm{Nn})-\mathrm{B}$ \\
5 & $\mathrm{Fm}(\mathrm{X})-\mathrm{A}$ & $\mathrm{Ld}(\mathrm{G})-\mathrm{B}$ & $\mathrm{Fm}(\mathrm{X})-\mathrm{NN}$ & $\mathrm{nn}(\mathrm{Nn})-\mathrm{A}$ & $\mathrm{nn}(\mathrm{Nn})-\mathrm{A}$ \\
6 & $\mathrm{Ld}(\mathrm{X})-\mathrm{A}$ & & $\mathrm{Fm}(\mathrm{X})-\mathrm{A}$ & $\mathrm{F}(\mathrm{Nn})-\mathrm{B}$ & $\mathrm{nn}(\mathrm{Nn})+\mathrm{NH}(\mathrm{P})-\mathrm{B}$ \\
7 & $\mathrm{~L}(\mathrm{X})-\mathrm{A}$ & & $\mathrm{Ld}(\mathrm{G})-\mathrm{A}$ & $\mathrm{nn}(\mathrm{Nn})-\mathrm{A}$ & $\mathrm{O}(\mathrm{C})-\mathrm{B}$ \\
8 & $\mathrm{Fm}(\mathrm{X})-\mathrm{A}$ & & $\mathrm{NH}(\mathrm{X})-\mathrm{B}$ & $\mathrm{nn}(\mathrm{Nn})-\mathrm{A}$ & \\
9 & $\mathrm{nn}+\mathrm{Ld}(\mathrm{X} / \mathrm{G})-\mathrm{NN}$ & & $\mathrm{Fm}(\mathrm{X})-\mathrm{NN}$ & $\mathrm{nn}(\mathrm{Nn})-\mathrm{A}$ & \\
10 & & & $\mathrm{Fm}(\mathrm{X})-\mathrm{A}$ & $\mathrm{nn}(\mathrm{Nn})-\mathrm{A}$ & \\
11 & & $\mathrm{Ld}(\mathrm{G})-\mathrm{A}$ & $\mathrm{Ld}(\mathrm{C}) \mathrm{nn}(\mathrm{Nn})-\mathrm{A}$ & \\
12 & & $\mathrm{Fm}(\mathrm{X})-\mathrm{NN}$ & & \\
13 & & $\mathrm{Fm}(\mathrm{X})-\mathrm{A}$ & & \\
14 & & $\mathrm{Fm}(\mathrm{X})-\mathrm{B}$ & & \\
15 & & $\mathrm{Ld}(\mathrm{X})-\mathrm{A}$ & & \\
16 & & $\mathrm{Ld}(\mathrm{X})-\mathrm{NN}$ & & \\
17 & & $\mathrm{Ld}(\mathrm{G})-\mathrm{NN}$ & & \\
\hline
\end{tabular}

House names: $L=$ Locality name, $L f=$ place name derived from field, $L d=$ Place deixis, $F=$ human name (often of founder), $\mathrm{Fm}=$ male founder, $\mathrm{Ff}=$ female founder, $\mathrm{NH}=$ New House, $0=$ other, $\mathrm{nn}=$ not known. Language of house name: $\mathrm{X}=$ Xumi/Shixing, $\mathrm{G}=\mathrm{Gami}, \mathrm{P}=$ Pumi, $\mathrm{C}=$ Chinese, $\mathrm{N}=$ Naxi, $\mathrm{Nn}=$ not known. Age of house: $\mathrm{A}=$ old, $\mathrm{B}=$ new, $\mathrm{NN}=$ not known.

Overall, the data on house names are least robust, as the recorded names are often based on information given by one single interlocutor in each village. Houses may furthermore have multiple appellations, depending on the social situation in which they are mentioned. Nevertheless, one may note that most houses whose name referred to a place name were old ones. There was a tendency not to name new houses after a locality (note that barely any of the new 30 Shuhi houses in the entire valley recorded in this survey was named by a deictic). It would also be interesting to further investigate whether giving the house a place name required ritual permission, e. g. from the $k l u$ and other numinous beings in the landscape. When a new house was named neither after a place nor a person, it was simply called the "New House". If naming the house after a place is taken as an indication of living in a hearth-oriented way, it would appear that this hearth-oriented attitude is not reinforced through the naming of most new Shuhi houses throughout the Shuiluo valley and in the south, in Mianbang, it was least embraced. 


\section{Conclusion}

In this article we investigated variations in kinship practices we considered 'hearth-oriented'. They were a) practices concerning the question of who would continue to live in the house of their parents, b) practices relating to the orientation in which the house and its places of worship were built in relation to the environment and c) practices regarding the naming of houses. We found significant variations in all practices along a north-south axis but also some striking continuities.

We investigated to what extent these variations may have been motivated by the increased socio-political presence of the PRC's legal and administrative reforms in the Shuiluo valley, on the one hand, and the Tibetan Buddhist revivalism, on the other. The current cash-economy-centred livelihood approach, an increased appreciation of state education and the influence of mass media might reflect recent trends of reformist China. On the other hand, Tibetan music, Tibetan Buddhist religious activities, Tibetan clothing and the adoption of Gami Tibetan language and ethnic identity indicated a strong Tibetan religious as well as cultural presence in the Shuiluo Valley.

Among the striking continuities of 'hearth-oriented' kinship practices throughout the last three generations belongs an insistence, particularly among the Lanman Shuhi, to accord the first-born the ritual prerogative to continue the house line, and thereby keep the house alive. This gender-blindness regarding the responsibilities of the first-born was observed also among a neighbouring people, the Lianmu Menggu (Na/Mosuo). The Lianmu Menggu said they were patrilineal but in fact continued endorsing such a gender-blind hearth-oriented kinship practice. The physical closeness of the administrative centre of Shuiluo Township with its Han values thus exerted a minimal effect on the Lianmu Menggu but had a great effect on the Pingweng Shuhi, as in the eleven houses visited, a shift in handing over the house to the first-born male offspring was strikingly apparent.

We also observed that despite Shuhi villages generally being built in clusters and despite other limitations of the physical terrain, it was possible to identify from the orientations of architectural features of the house, such as the orientation of the lhatse and ritual furnace on the flat roof of the houses, that people venerated the sacred mountains Chenrezig, Jampayang and Chenadorje overtowering the valley in the West. Meanwhile, we also recorded two distinctive orientations of how the hearth was built into the Shuhi houses of Lanman and Mianbang villages which both were very distinctively clustered. People were not asked to explain our findings, as those emerged only recently after extended analysis. Nor could we observe any gradients towards 
either Tibetan or Chinese values in how these practices of building houses and worship in the house changed along the north-south axis.

By contrast, the practices of naming the house were again among the Lanman Shuhi most distinctively oriented towards emphasizing place. New houses were generally not named according to place.

In summary, there are indices that the Shuhi did indeed engage in hearthoriented kinship practices, and continue doing so, but often in hybridized form.

Acknowledgements: Special thanks go to Professor Yang Yongping, Kunming Institute of Botany, Chinese Academy of Sciences, and Mr Chen Yulin, Kunming. A warm thank you also for the most helpful remarks of the two reviewers.

Funding: Weckerle and Huber obtained funding from the Swiss National Science Foundation (PBZHA-104354), among other stipends.

\section{References}

Blondeau, Anne-Marie / Steinkeller, Ernst (eds.) (1996): Reflections of the mountain. Essays on the History and Social Meaning of the Mountain Cult in Tibet and the Himalaya. Wien: Verlag der Oesterreichischen Akademie der Wissenschaften.

Büeler, Franziska (2010): Ethnobotanical Study among Ethnic Groups in the Shuiluo Valley, Southwest China: Local Knowledge of Ritual Plant Use. Unpublished Master's Thesis in Ethnobotany. Zürich: University of Zürich.

Carsten, Janet (ed.) (2000): Cultures of Relatedness: New Approaches to the Study of Kinship. Cambridge: Cambridge University Press.

Carsten, Janet / Hugh-Jones, Stephen (eds.) (1995): About the House: Lévi-Strauss and Beyond. Cambridge: Cambridge University Press.

Chirkova, Katia / Huber, Franz K. / Weckerle, Caroline S. / Daudey, Henriette / Pincuo, Gerong (2016): "Plant Names as Traces of the Past in Shuiluo Valley, China". Journal of Ethnobiology 36.1: 192-214.

Harrell, Stevan (2001): Ways of Being Ethnic in Southwest China. Seattle, WA: University of Washington Press.

Howell, Signe (1995): “The Lio House: Building, Category, Idea, Value”. In: About the Bouse: Lévi-Strauss and Beyond. Edited by Janet Carsten and Stephen Hugh-Jones. Cambridge: Cambridge University Press, 149-169.

Howell, Signe Lise (2003a): “Kinning: The Creation of Life Trajectories in Transnational Perspective". Journal of the Royal Anthropological Institute 9.3: 465-484.

Howell, Signe Lise (2003b): "The House as Analytic Concept: A Theoretical Overview". In: The House in Southeast Asia. Edited by Stephen Sparkes and Signe Howell. London: Routledge, 16-34.

Hsu, Elisabeth (1998a): “Introduction”. In: Naxi and Moso Ethnography: Kin, Rites, Pictographs. Edited by Michael Oppitz and Elisabeth Hsu. Zürich: Völkerkundemuseum, 9-19. 
Hsu, Elisabeth (1998b): “Moso and Naxi: The House”. In: Naxi and Moso Ethnography: Kin, Rites, Pictographs. Edited by Michael Oppitz and Elisabeth Hsu. Zürich: Völkerkundemuseum, 67-99.

Huber, Franz K. (2013): What Defines Sustainability? An Ecological and Societal Analysis of Wild Medicinal and Mushroom Collection with Respect to Livelihood Strategies in the Hengduan Mountains, Southwest China. PhD Thesis, Zürich: ETH Zürich.

Huber, Franz K. / Yang, Yongping / Weckerle, Caroline S. / Seeland, Klaus (2014): "Diversification of Livelihoods in a Society in Transition: A Case Study of Tibetan Communities in Southwest China". Society and Natural Resources 27.7: 706-723.

Knoedel, Susanne (1995): Die matrilinearen Mosuo von Yongning: Eine quellenkritische Auswertung moderner chinesischer Ethnographien. (The Matrilineal Moso of Yongning: A Critical Analysis of the Modern Chinese Ethnographies). Münster: Lit Verlag.

Levine, Nancy E. (1988): The Dynamics of Polyandry: Kinship, Domesticity, and Population on the Tibetan Border. Chicago: Chicago University Press.

Naef, Roland (1998): Das Haus bei den Lianmu-Menggu (Südwest-China). Unpublished Diploma Thesis in Social Anthropology. Zürich: University of Zürich.

Novellino, Dario (2009): “From 'Impregnation' to ‘Attunement': A Sensory View of How Magic Works". Journal of the Royal Anthropological Institute 15.4: 755-776.

Oppitz, Michael / Hsu, Elisabeth (eds.) (1998): Naxi and Moso Ethnography: Kin, Rites, Pictographs. Zürich: Völkerkundemuseum.

Rowlands, Mike / Fuller, Dorian Q. (2009): “Moudre ou faire bouillir?” Techniques \& Culture 52-53: 120-147.

Schiesser, Markus (2000): Haus und Raum bei den Siweng-Pumi in Südwest-China. Unpublished Diploma Thesis in Visual Anthropology. Zürich: University of Zürich.

Schneider, David M. (1961): “The Distinctive Features of Matrilineal Descent Groups”. In: Matrilineal Kinship. Edited by David M. Schneider and Kathleen Gough. Berkeley: University of California Press, 1-29.

Schneider, David M. (1984): A Critique of the Study of Kinship. Ann Arbor, MI: University of Michigan Press.

Shih, Chuan-kang (1993): The Yongning Moso: Sexual Union, Household Organization, Gender and Ethnicity in a Matrilineal Duolocal Society in Southwest China. Unpublished Doctoral Dissertation, Stanford University.

Shih, Chuan-kang (2010): Quest for Harmony: The Moso Traditions of Sexual Union and Family Life. Palo Alto, CA: Stanford University Press.

Sun, Hongkai (1990): “Languages of the Ethnic Corridor in Western Sichuan”. Translated by Jackson T.-S. Sun. Linguistics of the Tibeto-Burman Area 13.1: 1-31.

Weckerle, Caroline (1997): Der Gebrauch von Pflanzen im Alltag der Nanman-Shimi. Unpublished Diploma Thesis in Ethnobotany. Zürich: University of Zürich.

Weckerle, Caroline S. / Huber, Franz K. / Yang, Yongping / Sun, Weibang (2006): "Plant Knowledge of the Shuhi in the Hengduan Mountains, Southwest China”. Economic Botany 60: 3-23.

Wellens, Koen (2006): Consecrating the Premi house: Ritual, Community and the State on the Borderlands of East Tibet. Unpublished Doctoral Dissertation, Oslo: University of Oslo.

Wellens, Koen (2010): Religious Revival in the Tibetan Borderlands: The Premi of Southwest China. Seattle, WA: University of Washington Press.

Yang, Fuquan (1998): “The Ssu Life Gods and Their Cults”. In: Naxi and Moso Ethnography: Kin, Rites, Pictographs. Edited by Michael Oppitz and Elisabeth Hsu. Zürich: Völkerkundemuseum, 189-208. 